\title{
Enhancing the Listening and Speaking Skills Using Interactive Online Tools in the HEls Context
}

\author{
Dr. Amjed Ayyat $\mathrm{D} \otimes \mathbf{1}$, Ms. Asma Al-Aufi iD 2 \\ ${ }^{12}$ Senior lecturer, Middle East College, Center for Foundation Studies, Muscat, Oman \\ $\triangle$ Corresponding Author: Dr. Amjed Ayyat, E-mail: amjed@mec.edu.om
}

\section{ARTICLE INFORMATION}

Received: December 18, 2020

Accepted: February 12, 2021

Volume: 4

Issue: 2

DOI: $10.32996 /$ ijllt.2021.4.2.18

\section{KEYWORDS}

Listening and speaking skills, Technology and TESOL, GFP students

\section{ABSTRACT}

Online learning has become the most prominent teaching method utilized by Higher Education Institutions (HEIs) during the spread of COVID-19 pandemic. There are abundant online learning websites to practice reading skills, writing skills, vocabulary and grammar. However, there are very limited interactive websites for students to practice and develop their listening and speaking skills. Hence, this study, which was conducted in a private $\mathrm{HEl}$ in Oman, examines English Foundation students perspectives on the use of two distinctive websites; ESL-lab.com and Youglish.com. in enhancing their listening, speaking and pronunciation skills. The study employed a quantitative approach. An online survey was administered on (75) participants enrolled in the General Foundation Program (GFP) to explore their views on the chosen interactive websites. The main results revealed positive feedback from ESL students in which they were exposed to authentic conversational contexts, which accustomed them to different English -speaking and culture-specific lifestyles. Overall, the two websites proved to be highly interactive and effective in enhancing the listening, speaking and pronunciation skills of GFP students. Moreover, the researchers recommended that the two websites to be used in the Undergraduate (UG) modules level especially Youglish.com in which UG students can learn the pronunciation of the technical terms of their specializations.

\section{Introduction}

Due to the consequences that were brought abought by the spread of COVID-19 pandemic, many HEls in the world resorted to the online mode of learning. Lectures, professors and instructors started preparing synchronous and asynchronous materials to keep their students on the teaching/learning track. For instance, in the ESL field, and especially the GFP context, ESL instructors had a lot of challenges due to the nature of the skills that they are teaching which badly need a face-to-face interaction. Skills like writing, reading, listening and speaking can be taught interactively in the face-to-face mode. Students can do individual, pair, and group work easily. Simultaneously, ESL instructors can easily give their students individual and/or collective feedback. Moreover, extracurricular activities can be conducted easily and authentic environments and real-world contexts can be established to make the students use the English language in an authentic context. However, the spread of COVID-19 was unexpected, and almost all HEls were working on the face-to-face mode, which was suddenly replaced with a new mode, the online one. This unexpected change causes some confusion at the earliest stage. However, ESL instructors started working hard to prepare materials to their students to ensure the interactive use of the English language. Many interactive websites were available to the writing, reading, listening and speaking skills. However, it was very difficult to decide which ones are more effective, informative and useful to the students especially for the listening and speaking skills. The researchers resorted to two interactive websites namely; Esl-lab.com and Youglish.com.

It goes without saying that the listening and speaking skills are very important to learning any language. Maulana et.al (2020) believe that listening skills are the major skills of language which implies understanding the linguistic message of the speaker. It

K C AL-KINDI CENTER R FOR RESEARCH AND $R$ D DEVELOPMENT Your gateway to world-class research

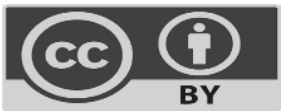

Published by Al-Kindi Center for Research and Development. Copyright (c) the author(s). This open access article is distributed under a Creative Commons Attribution (CC-BY) 4.0 license 
is regarded the first step in children's language acquisition. Therefore, in order to speak well, you need to listen first. At the same time, many researchers believe that the two skills should be taught at the same time and cannot be separated. For instance, Maulana et.al cited Yapping in which he claims that "listening and speaking are important for learning any language well and should not be separated through the process of teaching". Meanwhile, and since the online mode is less interactive than the face-to-face mode and in order to keep students engaged in the teaching/learning process, it was very important to bear this in mind that listening and speaking skills needs interaction in order to be more effective. Nunan (2004) affirmed that "communicative tasks are pieces of classroom work in which learners attempt to comprehend, manipulate, produce and interact in the target language". Furthermore, Wajnryp (1990) maintained that "through active learner involvement, students come to confront their own strengths and weaknesses in English language use. In so doing, they find out what they do not know, and then they find out what they need to know." Therefore, it is crucial for any Listening and speaking skills instructor to bear in mind that listening and speaking skills should be taught interactively. Furthermore, another crucial notion to make these two skills more effective is authenticity. It is well known that When people learn a foreign language, they usually want to make use of that language to communicate with people who speak the same language" (Davies, 2000). Byrne (1991) stated that "one should keep in mind that these skills are normally integrated in real life." Hence, two notions are crucially necessary to the success and effectiveness of listening and speaking skills teaching/learning, namely; Interaction and Authenticity.

\section{2- Statement of the problem}

The problem of the research was to evaluate the effectiveness of two interactive websites in teaching the listening and speaking skills to GFP students in the HEls in Oman. The two websites are: esl-lab.com and youglish.com.

\section{Esl-lab.com}

A website is designed in a way to suits students' different levels. There are three main levels: easy, intermediate and advanced. Furthermore, there are some activities for academic English. Each level is divided into different themes. These themes are really related to the students` interests and they are very important as they deal with the everyday issues. Each theme is divided into four main parts, the first part is the warming up part in which students are exposed to the theme through a speaking activity in which a general question which is related to the theme, is asked to the students. Then, some idiomatic expressions are introduced with their meaning and example. After that, the listening activity is introduced in which, at least, a three- minute audio is given and followed with (5) multiple -choice questions. The questions assess two important listening skills, namely; listening for the main idea and listening for specific details. Furthermore, filling the gap, sentence matching, vocabulary, grammar and other different activities are followed to enhance the understanding of the theme. Finally, another post-speaking activity is introduced.

\section{Youglish.com}

A website is similar to YouTube. It has a search engine, which has different dialects that a user can choose from. The main purpose of the website is to enable the students to listen to native speakers pronouncing the word, which they requested to hear by inserting it in the search engine. A video pops up with a speaker pronouncing the concerned word. The user can stop and repeat to the word to practice pronouncing it. More features are available such as subtitling and a dictionary to get the meaning of the word itself and other words that the user might not be familiar with.

\section{3-Research Hypotheses}

Based on the statement of the problem, the research hypotheses are mentioned below:

A- The two websites esl-lab.com and youglish.com are NOT effective in teaching the listening and speaking skills in the GFP context.

B- The two websites esl-lab.com and youglish.com are effective in teaching the listening and speaking skills in the GFP context.

\section{4- Literature Review}

Al-Jabri (2018) conducted a qualitative study to investigate the listening skills teaching for the English language in Oman for the $10^{\text {th }}$ grade at the public schools of the Ministry of Education. In her thesis, Al-Jabri noticed that the targeted subjects have low performance in the listening skills. Therefore, her study focused on different stakeholders to get their feedback on this issue. AlJabri focused on the curriculum, the policy of Ministry of Education and she interviewed the teachers, supervisors and the $10^{\text {th }}$ grade students as well. The sample of her thesis consisted of 10 participants. Data were collected through semi-structured interviews and a focused-group discussion. Her research revealed that there were many issues related to the curriculum. For instance, the curriculum lacked authentic contexts which are really effective to enhance the listening skills. Furthermore, there was an issue with the teaching approach which only focused on the product rather than the process itself. What is more, different problems such as clarity of the audios, speed, types of questions, exercises, complexity of the topics and the listening 
scripts played an essential role in the low performance of the $10^{\text {th }}$ grade students. Moreover, Al-Jabri found about that there was a gap among the designing of the previous curriculums which had no sequence in which some important skills are missing or overlapped. Finally, Al-Jabri recommended that further reconsideration should be taken into account to bridge the existing gaps in the curriculums and the policies followed and thus this will positively affect the teaching approach followed by the English language teachers. This will surely, according to her, contribute to increasing the performance of the $10^{\text {th }}$ grade students.

Maulana et.al (2020) conducted a research in which they aimed at coming up with a new teaching method to teach listening and speaking skills to Thais students who are learning classical Arabic. They focused on designing a communicative method that enables students to understand and produce classical Arabic-based conversations. Using a mixed method, Maulana et.al resorted to a quantitative and a qualitative approach to apply their schema. Therefore, they prepared two groups of university students; namely, the experiment group which has been exposed to the new technique and the control group which was taught by the traditional method. While applying the new method, Maulana et.al used several teaching techniques which are, according to them, crucial for teaching these two skills: dialogue, information exchange, role play, lecturing, debating, and discussion. In fact, during applying this method, Maulana et.al encountered some challenges which are introvert students who were reluctant to participate in the teaching/learning process. Moreover, another challenge which was faced was the availability of authentic texts of classical Arabic. Based on the cognitive theory, Maulana et.al claimed that listening and speaking skills are the skills which allow learners to communicate orally and thus they should be taught inseparably. In fact, according to them, their method was based on three pillar that went in line. These pillars are the linguistic features of the target language, the social features which are needed to successfully achieve communication and discourse analysis which helps students to differentiate among the different purposes of the linguistic outcomes. Maulana et.al summarized their new strategy into eight steps: (1) setting the teaching objectives, (2) Preparing the teaching materials which are based on the teaching techniques which are mentioned above, (3) ensuring their technique to be highly interactive, (4) exposing students to the materials available and prepared, (5) Discovering the potentials of each student during the teaching process, (6) mixing between the attitudinal teaching approach along with the functional situational one, (7) Encouraging students to get engaged in producing creative conversations based on the above mentioned steps, and finally (8) Giving feedback to the students to their grammar and pronunciation as well. The result of their newly introduced approach revealed that the experiment group achieved higher scores than the control one by conducting an end-to-method assessment. Furthermore, they recommended that this communicative approach should be used while teaching students classical Arabic. Also, original texts should be used during the application of this method. Finally, they maintained that communicative competencies should be taken into consideration by the instructor whose role in this approach is a task facilitator rather than a regular teacher.

Tavil (2010) conducted another study on teaching listening and speaking skills based on the notion of communicative competence. She claimed that teaching listening and speaking skills should never be separated. Taking in mind the notion of communicative competence, Tavil asserted on the fact that to achieve successful communication in oral skills, a second language learner should have excellent aural skills. Therefore, her study is based on the notion of teaching listening and speaking skills inseparably. Consequently, her study was conducted on (190) students from the preparatory school of Hecettepe University. The subjects of her research were divided into two even numbers. The first (90) students were taught listening and speaking skills separably. On the other hand, the second (90) students were taught the same skills in an integrated way. To collect her data, she prepared a t-test. This test has the same type of questions which is gap-filling. According to Travil, gap-filling exercises are the most suitable tasks that an ESL teacher can use inside his classroom. Her rational is based on the idea that such exercises give more confidence to the learners as they can be designed gradually from the easiest to the most difficult. Furthermore, such tasks can achieve the learning outcomes of teaching listening and speaking skills. Additionally, such tasks are natural and can allow the students to produce authentic output in the target language. To give validity and reliability to her study, Tavil conducted a pilot study in which she prepared a pre-post test which was carried out on (20) different students. The results of her study revealed that the students who were taught speaking and listening skills separately scored higher marks than those who were taught listening alone and speaking alone. Furthermore, those students who scored more were able to listen to authentic English language social situations more than those who were not. In addition, students who scored higher were able to produce nativelike outputs on the sentence level and the conversational level as well. Tavil concluded her study by maintaining that the success of students in mastering these two skills is increasing through teaching these two skills in an integrated way and using information-gap tasks.

Saricoban and Karakurt (2016) focused on task-based activities in their research. The purpose of their study was to figure out the effectiveness of introducing task-based activities in their listening and speaking classes. According to Saricoban and Karakurt, a task-based activity is an activity is an authentic activity which has meaning and structure. This task has a problem in which the teacher needs to facilitate to his/her students. Moreover, they claim that a task-based activity has five elements namely; goals, input, procedures, roles, and settings. Their method of collecting data was based on a mixed approach in which quantitative as 
well as qualitative tools were used. They divided their students into two groups. The first group (B1) is composed of (32) students. The second group (B1+) is composed of (24) students. The students were from different specializations. During the seven weeks in which the research was conducted, both groups were delivered listening and speaking classes. The first group (B1) was not given task-based activities at all. Whereas, the second group (B1+) was given. The tasks delivered were composed of three stages namely; a pre-task, task-cycle and language focus. Both groups were tested after the end of delivering classes. In order to validate the test which was used, it was given to a third group to check both its validity and reliability. Additionally, both researchers conducted separate interviews with the students reflecting on their experience with the task-based activities. The results showed that the students who were introduced to task-based activities scored higher marks than those who were not in both listening and speaking skills. Finally, Saricoban and Karakurt recommend task-based activities are effective tasks in which such tasks allow the students to express themselves freely. What is more, such tasks put the students in an authentic situation in which they can practise their English in a stress-free environment. The study recommends that the teacher should create an environment inside the classroom in which students can express themselves easily without any tension. In addition, the topics discussed inside the classroom should make the students engaged in the class. Therefore, students could simply link their inclass task-based activities with their use of the language outside the classroom.

Vasiljevic (2010) discusses the method of dictogless in her paper, and how it encourages collaborative work among students. She maintains that this method is highly effective for teaching the listening and the speaking skills. According to her, dictogless is a classroom activity, which is based on dictating a text to students for two times. The first-time students write only the keywords then they work in groups to write the completely dictated text. Moreover, dictogless method has consisted of four main stages, namely; warm-up in which the necessary vocabulary aisre introduced. Then, the dictation process in which students listen to the text twice and collect keywords. After that comes the reconstruction stage in which students work collaboratively to write the full text. Finally, the analysis and correction in which students get the feedback from their teacher. Vasiljevic claims that there are challenges that might be faced when implementing this method. One of these challenges is that some students might be reluctant to participate in this activity and they might lack confidence. She offers a solution to that by asking the teachers to create a positive atmosphere inside the classroom. Moreover, she advises the teachers to be positive inside the classroom by bringing up positive feedback and focus on the positive answers. Furthermore, she claims that dividing the students into homogeneous groups in which students get more relaxed and can start participating in the classroom. Vasiljevic ends up her article by maintaining that this method is incredibly effective as it encourages autonomous learning as well as collaborative practice among students. What is more, she claims that this approach results in engaging students actively in both skills; listening and speaking.

Ampa (2015) conducted a study on the effectiveness in using multimedia materials in teaching the listening skills only. The multimedia materials concerned were designed using the Wondershare Quizcreater program. According to her, such a program can allow the teacher to create interactive materials using videos and animation, which will enhance the student's engagement in the listening process. Furthermore, such a program allows the teachers to give on-going feedback while students are listening. Thus, this will make students more concentrated in the listening activities. Ampa claims that the problem of her research is that whether such multimedia activities can enhance the listening skills of her students. Therefore, she followed a quasi-experimental research approach in which she applied her approach onto two groups. The first group, the experimental one, is the one, which has been exposed to the multimedia materials. The second group, the control one, is the one, which has been exposed to the traditional approach in which students were given audios only during their listening classes. A pre-test and a post-test were designed and validated by experts. The two tests were given to the two groups. The pre-test results showed that the performance of the two groups were almost the same and there were no differences in the level of the two groups. On the other hand, and after the application of the adopted approach of using multimedia materials on the experimental group, the results have shown that the students of the experimental group scored higher marks than the students in the control group. Accordingly, Ampa concludes here paper by maintaining that using multimedia materials using Wondershare Quizcreater program is more effective than using the traditional way using audios only. Thus, such materials can engage student's interest in the listening classes and student can perform better.

\section{5-Methodology}

A qualitative research design was adopted in this study in which a survey with different types of questions was designed and distributed online to the participants.

\section{1- Subjects}

The number of participants were (75) divided into (25) in each session from the three different levels at GFP in Middle East College. Almost all the participants are Omani students and their ages are from 18 to 22 years old. They are all Muslims and they 
come from different regions from across Oman. All the participants had their secondary certificates from Omani public and/or private schools.

\section{2- Instrument}

The researchers used the two websites under investigations during summer 2020 in the listening and speaking classes. Participants were using the two websites asynchronously and synchronously. Feedback was given using different mechanisms. Collective and individual feedback was given during synchronous classes, whereas, during asynchronous use, students were given 0n-going feedback from the websites themselves for the listening exercises. On the other hand, online feedback was given to participants during the asynchronous use through an online application called Kaizala, specifically to the speaking activities. By the end of the term, an online survey was distributed to students online. Different questions were given and participants had the freedom to comment anonymously at the end of the survey.

\section{3- Data Collection}

The researchers had their data analyzed by using Google Forms. Bar charts along with pie charts were provided by Google Forms as well.

\section{4- Data Analysis and Procedure}

The researchers analyzed the data critically taking care of each question. The most distinctive questions were shed the light on in the results part.

\section{6- Results}

The gender of the participants was from both males and females. The females' percentage was (70.5\%) whereas the males' percentage was (29.5\%). Almost all the responses were positive. Some questions investigated the usefulness of the two websites. For instance, (64.1\%) of the participants found that esl-lab.com was an interesting website and the classes were really enjoyable and useful. Moreover, (57.7\%) of the participants described their experience using this website as useful. (30.8\%) of the participants found that the experience was funny and (42.2\%) of the participants described their experience as a positive one. None of the participants claimed that their experience was negative, (0\%).

Use one word or more to describe your experience with this website: (Select all the applicable)

75 responses

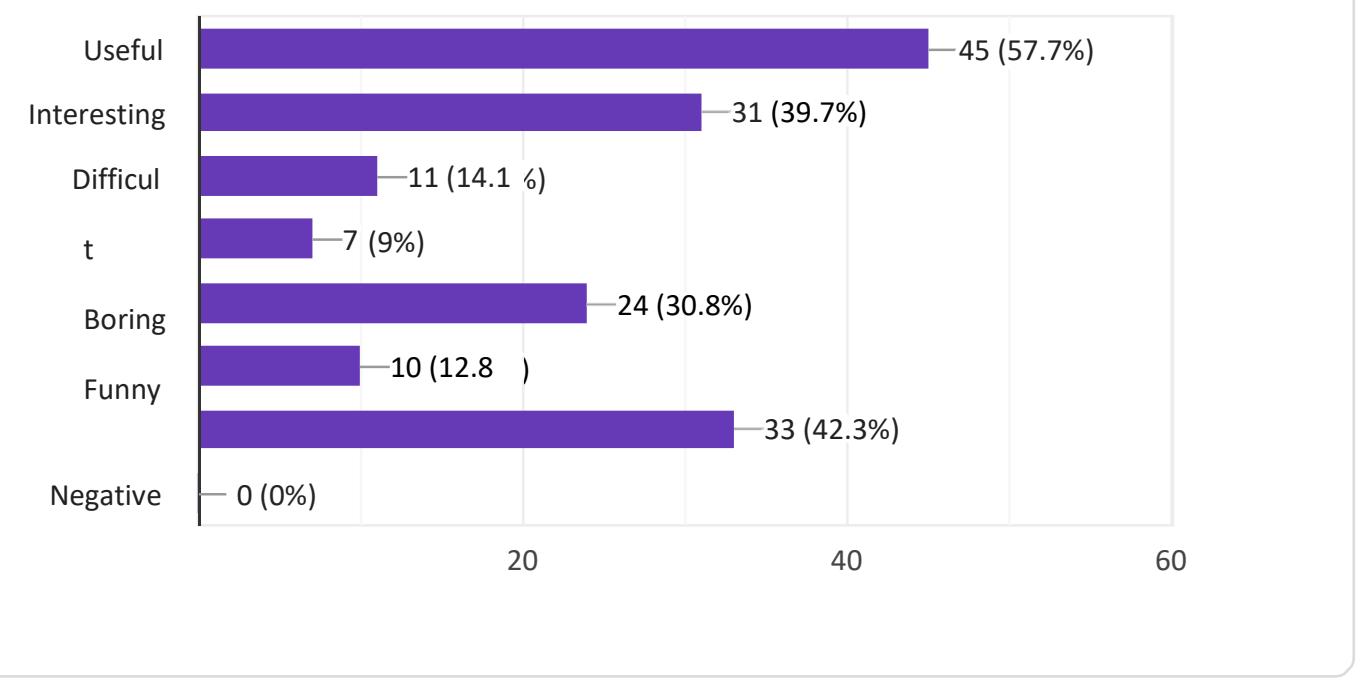

Figure (1) 
The topics used in the website (esl-lab.com) are:

75 responses

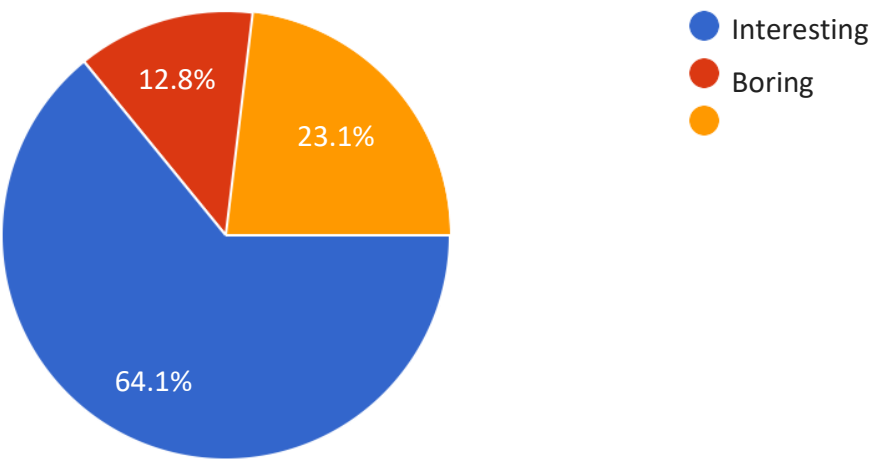

Figure (2)

For Youglish.com, the participants' responses were also positive. For instance, $(52.8 \%)$ of the participants described that their experience with this website was useful. Moreover, (38.5\%) claimed that their experience with the website was immensely positive. However, one participant (1.3\%) claimed that his/her experience with this website was negative.

Use one word or more to describe your experience with this website: (Select all the applicable)

78 responses

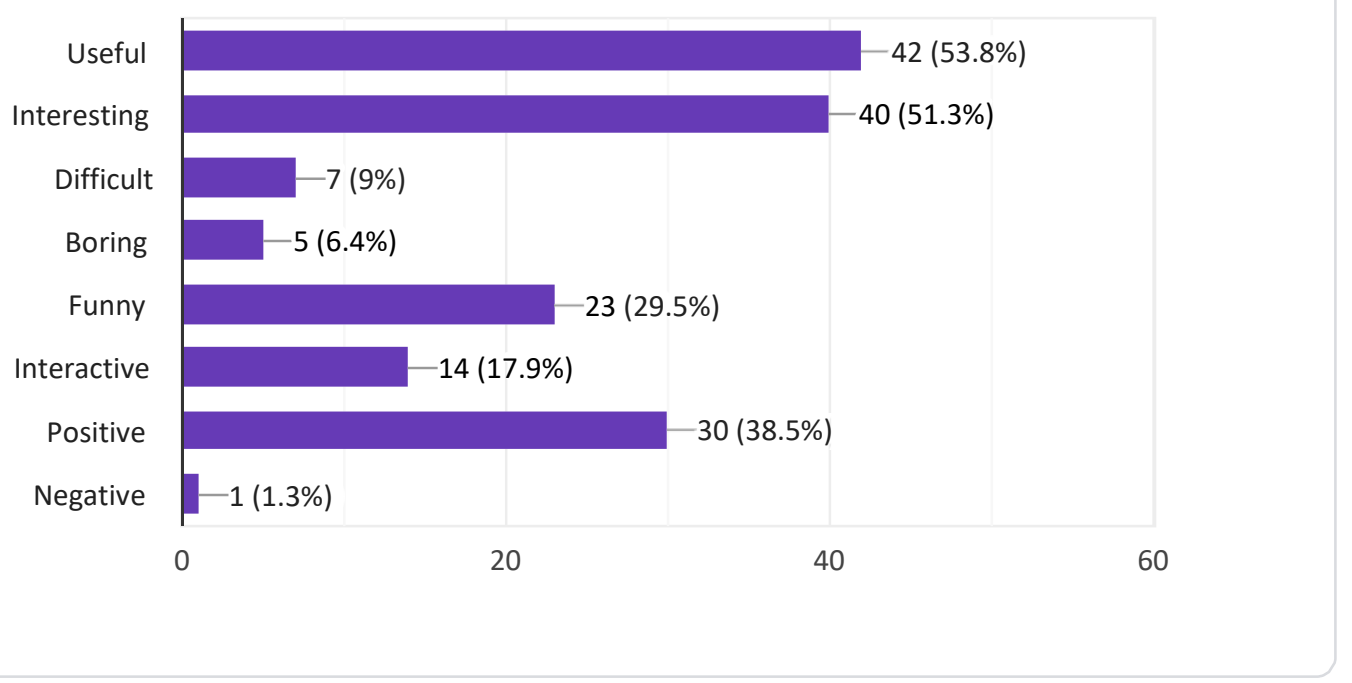

Figure (3) 
Most of the participants (80.8\%) claimed that they would continue using the two websites to improve their listening, speaking and pronunciation skills.

I will continue using these two websites to improve my listening, speaking and pronunciation skills.

75 responses

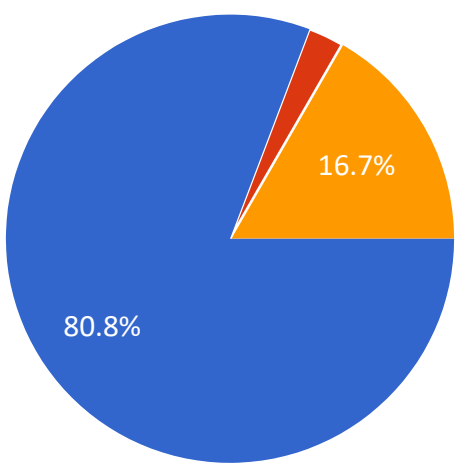

Figure (4)

It is worth mentioning that some participants commented on the two websites by answering an open-ended question in which few comments stated that the listening tracks available on esl-lab.com were a little bit difficult. On the other hand, a few comments about Youglish.com were stating that the usage of this website is not clear. We can claim that these comments were due to the usage of idioms, which were culture-specific. Furthermore, participants were sometimes using these two websites asynchronously and thus they needed help from their instructors to get the explanation of these idiomatic expressions and guidance to use these two websites successfully.

\section{7- Discussion}

It is obviously clear that the two websites are really effective and interesting. Furthermore, they can enhance the ESL students learning/teaching experience specifically in the listening and speaking skills. What is interesting about these two websites is that they can be used asynchronously and synchronously. Furthermore, they can be used simultaneously in which, students can listen to the track and pause it if a word's pronunciation or meaning is not clear on esl-lab.com. Consequently, meaning and/or pronunciation can be checked on youglish.com. Furthermore, the two websites are highly interactive and student can get an on-going feedback. This will enhance their autonomous learning experience and critical thinking as well.

\section{8- Conclusions and recommendations for further studies}

As it has been seen, the objectives of the study were to investigate whether the two websites namely; Esl-lab.com and Youglish.com are effective for teaching the listening and speaking skills. It has been proved by the feedback of the participants that the two websites are really effective and of great benefit to ESL students. This study has shed the light on the importance of both authenticity and interaction in teaching the above mentioned two skills. Authenticity is maintained through the topics being discussed in the first website, Esl-lab.com and through the availability of videos spoken by native speakers on the second website, Youglish.com. On the other hand, interaction is maintained through asking the participants to be involved in the activities and services provided by the two websites. The study does not focus on any other similar websites in order to get more reliable and specific results. Furthermore, other skills such as grammar were not examined. The researchers suggest that further studies should be conducted on other similar websites such as esl-longue.com for the listening skills. Furthermore, other skills should be examined along with other skill-related websites. For instance, COCA, english-corpora.org can be investigated for the writing and the grammar skills. Also, dreamreader.net can be investigated for the reading skills. 
Funding: This research received no external funding.

Acknowledgements: The authors extend their thanks to Middle East College, Muscat, Oman, for allowing them to conduct this research using its facilities.

Conflicts of Interest: The authors declare no conflict of interest.

\section{References}

[1] Al-Jabri, N. (2018). A Cace Study of the Discourses Governing Teaching and Learning L2 Listening in Grade 10 in Oman [ Master`s Thesis]. Sultan Qaboos University.

[2] Ampa, A. (2015). The Implementation of Interactive Multimedia Learning Materials in Teaching Listening Skills. English Language Teaching, 8 (12), 1916-4750.

[3] Byrne, D. (1991). Listening Comprehension 1. Cambridge University.

[4] Davies, P. (2000). Success in English Teaching. Oxford University Press.

[5] Maulana et.al (2020). The Efficiency of Teaching Listening and Speaking Skills to Develop Students`Communicative Competences. Universal Journal of Educational Research, 8 (3), 802-808.

[6] Nunan. D. (2004). Task-based Language Teaching. Cambridge University Press.

[7] Saricoban, A. and Karakurt. L. (2016). The Use of Task-Based Activities to Improve Listening and Speaking Skills in EFL Context. Sino-US English Teaching, 13 (6), 6,445-459.

[8] Tavil, Z. (2010). Integrating Listening and Speaking Skills to Facilitate English Language Learners`Communicative Competence. Procedia Social and Behavioral Sciences. 9: 765-770. Available online at www.sciencedirect.com

[9] Vasiljevic, Z. (2010). Dictogloss as an Interactive Method of Teaching Listening Comprehension to L2 Learners. English Language Teaching. 3(1). Available at www.ccsenet.org/elt

[10] Wajnryp, R. (1990). Grammar Dictation. Oxford University Press. 